An Introduction to Organometallic Chemistry 


\title{
An Introduction to Organometallic Chemistry
}

\author{
A. W. Parkins and R. C. Poller
}

King's College London

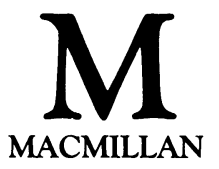


All rights reserved. No reproduction, copy or transmission of this publication may be made without written permission.

No paragraph of this publication may be reproduced, copied or transmitted save with written permission or in accordance with the provisions of the Copyright Act 1956 (as amended).

Any person who does any unauthorised act in relation to this publication may be liable to criminal prosecution and civil claims for damages.

First published 1986

Published by

Higher and Further Education Division

MACMILLAN PUBLISHERS LTD

Houndmills, Basingstoke, Hampshire RG21 2XS

and London

Companies and representatives

throughout the world

British Library Cataloguing in Publication Data

Parkins, A. W.

An introduction to organometallic chemistry.

1. Organometallic compounds

I. Title II. Poller, R. C.

547'.05 QD411

ISBN 978-0-333-36433-8

ISBN 978-1-349-18198-8 (eBook)

DOI 10.1007/978-1-349-18198-8 


\section{CONTENTS}

Preface

Abbreviations Used

1 Introduction

1.1 Scope

1.2 History

1.3 Nomenclature

1.4 Conventions

1.4.1 The eighteen electron rule

1.4.2 Periodic table

1.4.3 Additions to alkenes and Markownikoff's rule

1.5 Literature

1.5.1 Textbooks

1.5.2 Reviews and journals 9

References

General reading

2 Preparation of Organometallic Compounds

2.1 The direct reaction: starting with the metal 12

$\begin{array}{lll}2.1 .1 & \text { Mechanistic considerations } & 14\end{array}$

$\begin{array}{ll}2.2 \text { Starting with organometallic reagents } & 18\end{array}$

2.2.1 Reaction of organometallic reagents with metal halides $\quad 18$

2.2.2 Reaction of organometallic reagents with metal compounds or free metals 21

2.2.3 Reaction of organometallic reagents with organic halides 22

2.2.4 Reaction of organometallic reagents with unsaturated compounds 23

2.3 Metallation: direct replacement of hydrogen by a metal 25

2.4 Starting with alkenes, alkynes or arenes 28

2.4.1 Simple additions $\quad 29$

2.4.2 Preparation of $\pi$-bonded compounds 31

2.5 Electrochemical methods $\quad 35$

2.5.1 Cathodic processes $\quad 35$

2.5.2 Anodic processes $\quad 36$ 
2.6 Miscellaneous methods

References

General reading

3 Structure and Bonding in Organometallic Compounds 42

$3.1 \sigma$-bonded compounds $\quad 42$

3.1.1 Group I derivatives $\quad 43$

3.1.2 Group II derivatives $\quad 45$

3.1.3 Group III derivatives 46

3.1.4 Group IV derivatives $\quad 48$

3.1.5 Group V derivatives $\quad 49$

3.1.6 Group VI derivatives $\quad 50$

3.1.7 Group VII derivatives $\quad 51$

3.1.8 Group VIII derivatives $\quad 52$

3.2 Carbene and carbyne complexes $\quad 52$

$3.3 \pi$-complexes $\quad 54$

3.3.1 Mono-alkene (olefin) complexes $\quad 56$

3.3.2 Alkyne complexes $\quad 58$

3.3.3 Complexes of conjugated dienes $\quad 59$

3.3.4 $\eta^{3}$-Allyl complexes ( $\pi$-allyl complexes) 61

3.3.5 $\eta^{5}$-Cyclopentadienyl complexes 63

3.3.6 $\eta^{6}$-Arene complexes $\quad 69$

3.3.7 Cyclooctatetraene complexes $\quad 71$

3.4 Dynamic behaviour of organometallic compounds in solution $\quad 72$

$\begin{array}{lll}3.4 .1 & \eta^{1} \text {-Cyclopentadienyl compounds } & 72\end{array}$

$\begin{array}{ll}\text { 3.4.2 Mono-alkene complexes } & 73\end{array}$

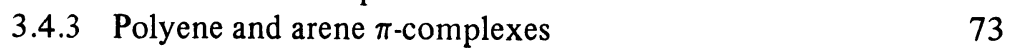

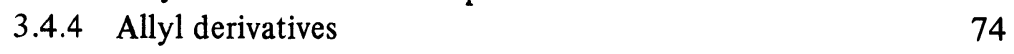

3.5 Thermochemistry of organometallic compounds $\quad 75$

References $\quad 76$

$\begin{array}{ll}\text { General reading } & 79\end{array}$

4 Organometallic Compounds as Sources of Carbanions 80

4.1 Generation and stability of carbanions 81

4.2 Electrophilic substitution at carbon $\quad 84$

4.3 Carbanions as nucleophilic reagents 90

4.4 Metallation and determination of acid strengths $\quad 94$

References $\quad 96$

$\begin{array}{ll}\text { General reading } & 97\end{array}$

5 Reactions of Organic Groups Bonded to Metals in Which the

Metal-Carbon Bond is Retained $\quad 98$

$\begin{array}{lll}5.1 & \sigma \text {-bonded compounds } & 98\end{array}$

5.1.1 Main group compounds with saturated organic groups 100 
5.1.2 Main group compounds with unsaturated organic groups 101

5.1.3 Main group compounds with aryl groups 103

$5.2 \pi$-bonded complexes

104

5.2.1 Ferrocene 104

5.2.2 $\eta^{5}$-Cyclopentadienyl complexes other than ferrocene 108

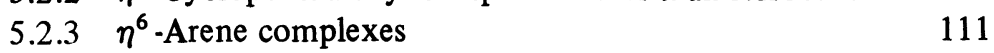

5.2.4 Tricarbonyl(diene)iron complexes 114

5.2.5 Diene complexes of palladium and platinum 115

5.2.6 Generalisations concerning nucleophilic addition to $\pi$-complexes $\quad 116$

References

116

General reading

118

6 The Coordination Chemistry of Organometallic Compounds

6.1 General survey

6.2 Effects on structure

6.2.1 Auto-complexation 122

6.2.2 Adducts of organometallic compounds 123

$\begin{array}{lll}6.3 & \text { Effects on reactivity } & 124\end{array}$

6.3.1 Oxidative addition and reductive elimination $\quad 124$

6.3.2 Migratory insertion reactions 127

6.3.3 Effects on electrophilic substitutions 129

6.3.4 Reactions proceeding by charge- and electron-transfer mechanisms 130

6.3.5 Homolytic reactions 133

References 134

$\begin{array}{ll}\text { General reading } & 135\end{array}$

7 Carbene Chemistry and Organometallic Compounds 136

$\begin{array}{lll}7.1 & \text { Carbene complexes derived from metal carbonyls } & 137\end{array}$

7.2 Routes to heterocarbene complexes not involving metal
carbonyls

7.3 Reactions of heterocarbene complexes 142

7.4 Conversion of heterocarbene complexes to carbyne complexes 146

7.5 Carbene complexes formed by $\alpha$-hydrogen abstraction (alkylidene complexes)

7.6 Reactions of high oxidation state alkylidene and alkylidyne complexes

7.7 Carbene complexes as intermediates in olefin metathesis $\quad 150$

7.8 The Fischer-Tropsch synthesis 152

7.9 Mercury derivatives as a source of carbenes 154

References $\quad 155$

$\begin{array}{ll}\text { General reading } & 156\end{array}$ 
8 Stoicheiometric Applications of Organometallic Compounds to Organic Chemistry

8.1 Main group element compounds 158

$\begin{array}{ll}\text { 8.1.1 Organolithium compounds } & 158\end{array}$

8.1.2 Organomagnesium compounds 162

8.1.3 Organomercury compounds 167

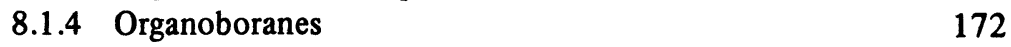

8.1.5 Organoaluminium compounds 175

$\begin{array}{ll}\text { 8.1.6 Organosilicon compounds } & 175\end{array}$

$\begin{array}{ll}\text { 8.1.7 Organotin compounds } & 182\end{array}$

8.2 Transition metal compounds $\quad 185$

8.2.1 Organocopper compounds 186

$\begin{array}{lr}\text { 8.2.2 Organotitanium compounds } & 189\end{array}$

8.2.3 Organoiron compounds 191

8.2.4 Organocobalt compounds 196

$\begin{array}{ll}\text { 8.2.5 Organonickel compounds } & 197\end{array}$

8.2.6 Organozirconium compounds 199

8.2.7 Organorhodium compounds 202

8.2.8 Organopalladium compounds 204

8.2.9 Organochromium compounds 208

References 210

General reading $\quad 213$

9 Catalytic Applications of Organometallic Compounds 214

9.1 Hydrogenation of unsaturated hydrocarbons 216

9.1.1 Hydrogenation using $\left(\mathrm{Ph}_{3} \mathrm{P}\right)_{3} \mathrm{RhCl} 216$

9.1.2 Hydrogenation using other rhodium and iridium catalysts 217

9.1.3 Asymmetric hydrogenation 218

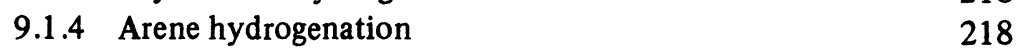

$\begin{array}{ll}9.2 & \text { Reactions involving carbon monoxide } \\ 9 & 219\end{array}$

9.2.1 Hydroformylation 219

9.2.2 Carboxylation reactions 223

9.2.3 Carbonylation of methanol 225

9.3 Reactions of unsaturated hydrocarbons involving C-C coupling 226

9.3.1 Chain growth of aluminium alkyls and alkene oligomerisation

9.3.2 Dimerisation of alkenes 228

9.3.3. Polymerisation of alkenes 229

$\begin{array}{ll}\text { 9.3.4 Polymerisation of butadiene } & 232\end{array}$

9.3.5 Oligomerisation of butadiene 233

9.3.6 Cyclotrimerisation of alkynes 234

$\begin{array}{ll}\text { 9.3.7 Isomerisation of alkenes } & 237\end{array}$

9.4 Oxidation of alkenes $\quad 238$

9.5 Hydrosilation 241 
9.6 Synthesis of substituted alkenes using palladium complexes

9.7 Transition metal catalysis with Grignard reagents

9.8 Main group catalysis

References

General reading 


\section{PREFACE}

The aim of this book is to provide a concise introduction to organometallic chemistry. The book is intended primarily for senior undergraduate and postgraduate students. Teachers and research workers may also find it useful to consult for specialised information.

We have used an integrated approach to discuss the organometallic chemistry of both transition-metal and main-group elements, making comparisons and contrasts where appropriate. We are aware that organic and inorganic chemists view the subject somewhat differently but have attempted to write a balanced non-partisan account. In writing a relatively short book which gives an overall impression of an immense field, we have had to make some difficult choices. This has led to some chapters being presented in a closely packed style, although we have written the chapters dealing with the principles of the subject in a more discursive explanatory manner. After some thought we decided to give a substantial number of references to key reviews and research papers, so that the book can serve as a guide to the literature of organometallic chemistry.

We are most grateful to Dr D. A. Armitage and Professor A. G. Davies for reading the complete manuscript and making helpful suggestions. We also thank Mrs E. A. Moor for her virtuoso typing of the text and diagrams.

It is unlikely, despite such excellent help, that the book is free from errors. The responsibility for these rests with us, and we welcome comments and criticisms from readers.

London, October, 1984

A. W.P.

R. C.P. 


\section{ABBREVIATIONS USED}

$\begin{array}{ll}\text { Ac } & \text { acetyl } \\ \text { acac } & \text { acetylacetonate anion } \\ \text { ACMP } & o \text {-anisylcyclohexylmethylphosphine } \\ \text { AIBN } & \text { azobisisobutyronitrile } \\ \text { BASF } & \text { Badische Anilin und Soda Fabrik } \\ \text { Bu } & n \text {-butyl } \\ \text { CHIRAPHOS } & \text { chiral 2,3-bis(diphenylphosphino)butane } \\ \text { COD } & \text { cycloocta-1,5-diene } \\ \text { COT } & \text { cyclooctatetraene } \\ \text { Cp } & \text { cyclopentadienyl } \\ \text { Cy } & \text { cyclohexyl } \\ \text { DIOP } & \text { chiral 2,3-O-isopropylidene-2,3-dihydroxy-1,4- } \\ & \text { bis(diphenylphosphino)butane } \\ \text { DMSO } & \text { dimethyl sulphoxide } \\ \text { dppe } & 1,2 \text {-bis(diphenylphosphino)ethane } \\ \text { e.s.r. } & \text { electron spin resonance } \\ \text { Et } & \text { ethyl } \\ \text { HMB } & \text { hexamethylbenzene } \\ \text { HMPT } & \text { hexamethylphosphoric triamide } \\ \text { HOMO } & \text { highest occupied molecular orbital } \\ \text { HSAB } & \text { hard and soft acids and bases } \\ \text { ICI } & \text { Imperial Chemical Industries } \\ \text { iPr } & \text { isopropyl } \\ \text { IUPAC } & \text { International Union of Pure and Applied Chemistry } \\ \text { L } & \text { unidentate ligand } \\ \text { LUMO } & \text { lowest unoccupied molecular orbital } \\ \text { Me } & \text { methyl } \\ \text { n.m.r. } & \text { nuclear magnetic resonance } \\ \text { Np } & \text { neopentyl } \\ \text { Ph } & \text { phenyl } \\ \text { phen } & 1,10 \text {-phenanthroline } \\ \text { Pr } & n \text {-propyl } \\ \text { py } & \text { pyridine } \\ \text { r.t. } & \text { room temperature } \\ \text { sBu } & s \text {-butyl } \\ \text { solv } & \text { solvent } \\ & \end{array}$


xii ABBREVIATIONS USED

$\mathrm{tBu}$ $t$-butyl

TCNE tetracyanoethene

TMED $N, N, N^{\prime}, N^{\prime}$-tetramethylethylenediamine

THF tetrahydrofuran

Tol p-tolyl

Ts $p$-toluenesulphonyl 